Article

\title{
Modeling of Sedimentation and Creaming in Suspensions and Pickering Emulsions
}

\author{
Rajinder Pal \\ Department of Chemical Engineering, University of Waterloo, Waterloo, ON N2L 3G1, Canada; \\ rpal@uwaterloo.ca; Tel.: +1-519-888-4567 (ext. 32985)
}

Received: 20 September 2019; Accepted: 18 October 2019; Published: 22 October 2019

check for updates

\begin{abstract}
Suspensions and emulsions are prone to kinetic instabilities of sedimentation and creaming, wherein the suspended particles and droplets fall or rise through a matrix fluid. It is important to understand and quantify sedimentation and creaming in such dispersed systems as they affect the shelf-life of products manufactured in the form of suspensions and emulsions. In this article, the unhindered and hindered settling/creaming behaviors of conventional emulsions and suspensions are first reviewed briefly. The available experimental data on settling/creaming of concentrated emulsions and suspensions are interpreted in terms of the drift flux theory. Modeling and simulation of nanoparticle-stabilized Pickering emulsions are carried out next. The presence of nanoparticles at the oil/water interface has a strong influence on the creaming/sedimentation behaviors of single droplets and swarm of droplets. Simulation results clearly demonstrate the strong influence of three-phase contact angle of nanoparticles present at the oil/water interface. This is the first definitive study dealing with modeling and simulation of unhindered and hindered creaming and sedimentation behaviors of nanoparticle-stabilized Pickering emulsions.
\end{abstract}

Keywords: Pickering; emulsion; suspension; droplet; nanoparticles; creaming; sedimentation; drift flux; Stokes law; contact angle

\section{Introduction}

Emulsions and suspensions form a large group of materials of industrial importance [1]. In suspensions, the dispersed phase consists of fine insoluble solid particles whereas in emulsions the dispersed phase consists of fine immiscible liquid droplets. In conventional emulsions, the dispersed droplets are stabilized against coalescence by the presence of surfactant at the oil-water interface. Pickering emulsions are a special class of emulsions where the dispersed droplets are stabilized against coalescence by solid nanoparticles which accumulate at the oil-water interface and provide steric barrier against intimate contact and coalescence between approaching droplets [2-11]. Thus Pickering emulsions are surfactant-free (see Figure 1). As Pickering emulsions are free of surfactants, they can replace conventional emulsions in household and personal care products where surfactants are known to exhibit adverse effects such as skin and eye irritation $[5,12]$. Due to outstanding properties of Pickering emulsions, there has been a rapid growth of interest in such systems recently [2-35]. In interfacial catalysis, the solid nanoparticles placed at the oil-water interface can be used to serve the dual purpose of catalyst and emulsion stabilizer [22-26]. Furthermore, chemical reactions can be carried out simultaneously in both aqueous and non-aqueous phases by placing solid catalyst nanoparticles at the oil-water interface [22-26]. Figure 2 shows a cryo-SEM image of an aqueous droplet of Pickering emulsion covered with silica nanoparticles [35]. The cryo-SEM image shows that the silica nanoparticles present at the interface are closely packed and they form a shell on the droplet. 


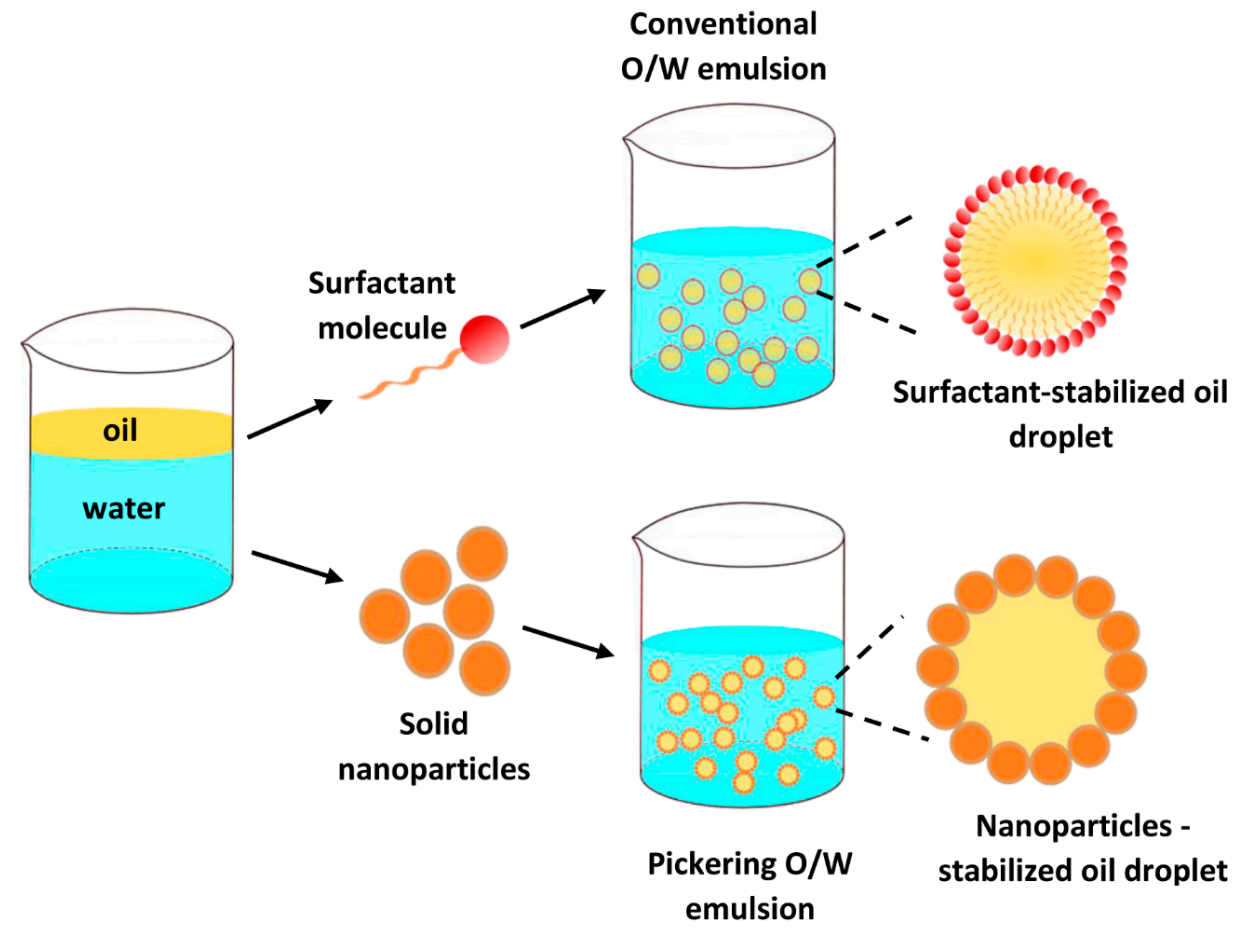

Figure 1. Schematic representation of conventional surfactant-stabilized and Pickering nanoparticle-stabilized oil-in-water $(\mathrm{O} / \mathrm{W})$ emulsions (Adapted with permission from [11]).

\section{Cryo-SEM image of aqueous Pickering droplet}

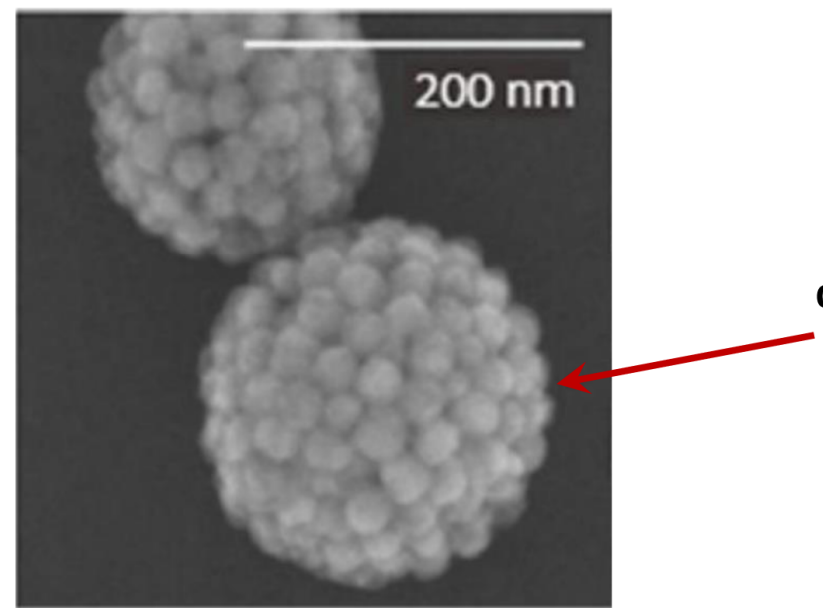

Aqueous Pickering droplet covered with silica nanoparticles of diameter $22 \mathrm{~nm}$

Figure 2. A cryo-scanning electron microscopy (cryo-SEM) image of droplet of W/O Pickering emulsion (Adapted with permission from [35]).

For nanoparticles to adsorb at the oil-water interface, it is necessary that the nanoparticles are partially wetted by both water and oil phases. Thus three-phase contact angle of nanoparticles is important [2-10]. If the contact angle measured through the aqueous phase is less than $90^{\circ}$, the nanoparticles are preferentially wetted by the aqueous phase. In such situations, oil-in-water $(\mathrm{O} / \mathrm{W})$ type of emulsions are favored. When the contact angle is greater than $90^{\circ}$, the nanoparticles are relatively more wetted by the oil phase [10]. In such situations, water-in-oil (W/O) emulsions are favored. A large variety of nanoparticles, inorganic and organic, exhibit partial wetting characteristics $[3-8,18]$ and hence are suitable for stabilization of emulsions. 
Sedimentation and creaming, wherein particles or droplets fall or rise through a fluid in which they are suspended under the influence of gravity, is a common occurrence in suspensions and emulsions [36,37]. Sedimentation and creaming are usually undesirable as they affect the shelf-life of the product. According to some estimates [37], nearly $40 \%$ of the cost of developing a new food emulsion product is incurred in testing of the shelf-life. Creaming and sedimentation are kinetic instabilities that not only affect the uniformity (uniform distribution of droplets) of the product, they are also precursors to thermodynamic instabilities [38]. For example, a creamed oil-in-water emulsion consisting of a concentrated layer of oil droplets at the top of the sample tends to coalesce (thermodynamic instability) faster due to close proximity of oil droplets in the creamed layer. Thus a good understanding of the sedimentation and creaming behaviors of emulsions and suspensions is important in the formulation, handling, processing, and storage of such dispersed systems.

The objectives of this work are as follows: (a) to briefly review the unhindered and hindered settling/creaming behaviors of conventional emulsions and suspensions; (b) to interpret the existing hindered settling/creaming experimental data on conventional emulsions and suspensions in terms of the drift flux theory; (c) to develop a new model for unhindered and hindered settling/creaming of nanoparticle-stabilized Pickering emulsions; and (d) to simulate the settling/creaming behavior of Pickering emulsions using the proposed model.

\section{Theoretical Background}

\subsection{Settling of a Single Rigid Particle}

Consider a rigid particle of mass $m$ settling in a liquid matrix under the action of a gravitational force. The forces acting on the particle are: gravity force $\left(F_{G}\right)$, drag force $\left(F_{D}\right)$, and buoyancy force $\left(F_{B}\right)$. Thus the net force acting on the particle in the downward direction is:

$$
F_{\text {net, downward }}=m \frac{d U}{d t}=F_{G}-F_{B}-F_{D}
$$

The gravitational force $F_{G}$ on the particle is equal to $m g$, the drag force $F_{D}$ on the particle is equal to $C_{D} A_{p}\left(\rho U^{2} / 2\right)$, where $C_{D}$ is the drag coefficient and $A_{p}$ is the projected area of the particle measured in a plane normal to direction of motion of particle (for spherical particle, $A_{p}=\pi R^{2}$ ), and the buoyancy force $F_{B}$ on the particle is equal to weight of the fluid displaced by the particle, that is, $F_{B}=m \rho g / \rho_{p}$ where $\rho_{p}$ is particle density. Thus:

$$
m \frac{d U}{d t}=m g-\frac{m g \rho}{\rho_{p}}-\frac{C_{D} A_{p} \rho U^{2}}{2}
$$

or,

$$
\frac{d U}{d t}=g\left(\frac{\rho_{p}-\rho}{\rho_{p}}\right)-\frac{C_{D} A_{p} \rho U^{2}}{2 m}
$$

Under steady state condition $(d U / d t=0)$, the particle settles at a constant velocity called the terminal velocity. Thus:

$$
U_{0}=\sqrt{\frac{2 g m\left(\rho_{p}-\rho\right)}{A_{p} \rho_{p} C_{D} \rho}}
$$

For spherical particles:

$$
m=\frac{\pi D_{p}^{3} \rho_{p}}{6} \quad \text { and } \quad A_{p}=\frac{\pi D_{p}^{2}}{4}
$$


This leads to the following settling velocity of spherical particles:

$$
U_{0}=\sqrt{\frac{4 g\left(\rho_{p}-\rho\right) D_{p}}{3 C_{D} \rho}}
$$

The drag coefficient is a function of the particle Reynolds number $\left(\operatorname{Re}_{p}\right)$, defined as:

$$
\operatorname{Re}_{p}=\frac{\rho D_{p} U_{0}}{\mu}
$$

For creeping flow around a spherical particle $\left(\operatorname{Re}_{p}<0.1\right), C_{D}$ is given by the Stokes Law as:

$$
C_{D}=\frac{24}{\operatorname{Re}_{p}}
$$

Upon substitution of the expression for $C_{D}$ into Equation (6), the following expression for the terminal settling velocity of spherical rigid particles is obtained:

$$
U_{0}=\frac{g D_{p}^{2}\left(\rho_{p}-\rho\right)}{18 \mu} \operatorname{Re}_{p}<0.1
$$

\subsection{Settling of a Swarm of Particles (Hindered Settling)}

In the preceding section, the settling behavior of a single rigid particle in quiescent fluid is discussed. In practical applications, sedimentation of a swarm of particles is important. Due to hydrodynamic interactions between the neighboring particles, the settling velocity of a swarm of particles is hindered or slower. When a swarm of particles settle, the suspending medium fluid moves upward in order to compensate for the settling of particles (see Figure 3). Due to the backflow drag on the particles, the particles settle at a velocity lower than that of an isolated article.

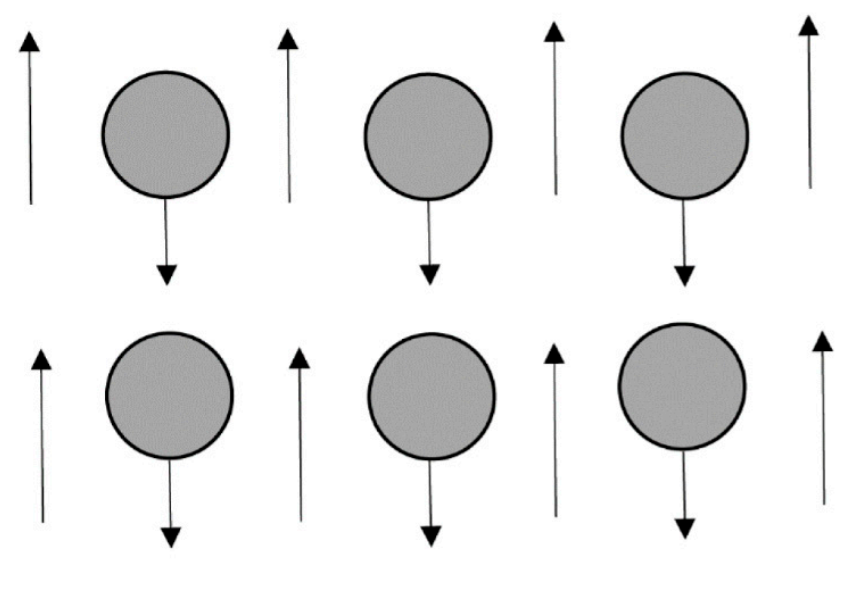

\section{Particles settling in the downward direction with respect to a stationary observer}

Matrix fluid moving in the upward direction with respect to a stationary observer

\section{Hindered Batch Settling (bulk suspension velocity is zero)}

Figure 3. Hindered batch settling of particles. 
The relative decrease in the settling velocity of particles in a dilute suspension is proportional to $\phi$, the volume fraction of particles, and is given as:

$$
\frac{U_{p}-U_{0}}{U_{0}}=-\alpha \phi
$$

where $U_{p}$ is the settling velocity of particles in a suspension of concentration $\phi$. Equation (10) can be re-written as:

$$
U_{p}=U_{0}(1-\alpha \phi)
$$

Assuming the spatial distribution of particles to be random, Batchelor [39] theoretically found the value of $\alpha$ to be 6.55 .

The linear relationship, Equation (11), is valid only at low concentrations $(\phi<0.05)$. At high particle concentrations, the hindrance effect becomes more pronounced and the relationship becomes non-linear. A number of empirical and semi-empirical correlations have been proposed in the literature to describe hindered settling of particles at high particle concentrations. The most popular ones are due to Richardson and Zaki [40] and Garside and Al-Dibouni [41]. The Richardson and Zaki correlation is given as:

$$
U_{p}=U_{0}(1-\phi)^{n}
$$

where $n$ is a function of particle Reynolds number $\operatorname{Re}_{p}$. For low $\operatorname{Re}_{p}\left(\operatorname{Re}_{p}<0.2\right), n=4.65$. The Garside and Al-Dibouni correlation is given as:

$$
\frac{U_{R}-A}{B-U_{R}}=0.06\left(\operatorname{Re}_{p}\right)^{\varepsilon+0.2}
$$

where $A=\varepsilon^{4.14}, B=0.8 \varepsilon^{1.28}$ (when $\varepsilon \leq 0.85$ ), $B=\varepsilon^{2.65}$ (when $\varepsilon>0.85$ ), $\varepsilon$ is volume fraction of fluid, and $U_{R}$ is defined as:

$$
U_{R}=\frac{U_{p}}{\varepsilon U_{0}}
$$

In the limit $\operatorname{Re}_{p} \rightarrow 0$, Equation (13) reduces to:

$$
U_{p}=U_{0}(1-\phi)^{5.14}
$$

This equation has the same form as that of the Richardson and Zaki equation, Equation (12), with a different value of $n$. Al-Naafa and Sami-Selim [42] proposed the following equation to describe their data on sedimentation of monodisperse suspensions:

$$
U_{p}=U_{0}(1-\phi)^{6.55}
$$

In the limit $\phi \rightarrow 0$, Equation (16) reduces to Batchelor's equation, Equation (11) with $\alpha=6.55$.

\section{Drift Flux Theory and Re-Interpretation of Existing Hindered Settling Data}

\subsection{Drift Flux Theory}

The drift flux theory is used widely in the analysis of two-phase flows when the two phases move with different velocities. For example, it can be used to predict the in-situ gas hold up in bubbly gas-liquid two-phase flows from the knowledge of superficial gas and liquid velocities, bubble size, and fluid properties. The drift flux theory can be readily applied to sedimentation of particles in non-dilute suspensions. The advantage of the drift flux theory is that it can applied to both batch sedimentation and continuous sedimentation of suspensions. Note that in batch sedimentation there is no net motion of suspension, that is, the particles and the matrix fluid move in opposite directions such that the net 
suspension velocity is zero with respect to a stationary observer. In continuous sedimentation, the suspension has a net motion with a non-zero net velocity with respect to a stationary observer.

Consider a suspension of solid particles in Newtonian liquid. The drift velocity of solid particles, denoted as $\vec{U}_{p m}$, is defined as:

$$
\vec{U}_{p m}=\vec{U}_{p}-\vec{U}_{m}
$$

where $\vec{U}_{p}$ is the particle velocity and $\vec{U}_{m}$ is the mixture (suspension) velocity with respect to a stationary observer. Thus the drift velocity of a particle is the velocity of a particle relative to an observer moving with the suspension velocity $\vec{U}_{m}$. The suspension velocity $\vec{U}_{m}$ can be expressed as:

$$
\vec{U}_{m}=\vec{J}_{p}+\vec{J}_{l}
$$

where $\vec{J}_{p}$ is the volumetric flux of particles and $\vec{J}_{l}$ is the volumetric flux of liquid phase. The volumetric fluxes are related to particle and liquid velocities as follows:

$$
\begin{gathered}
\vec{J}_{p}=\phi \vec{U}_{p} \\
\vec{J}_{l}=(1-\phi) \vec{U}_{l}
\end{gathered}
$$

where $\vec{U}_{l}$ is the liquid phase velocity. From Equations (17) and (18), it follows that:

$$
\vec{U}_{p m}=\vec{U}_{p}-\left(\vec{J}_{p}+\vec{J}_{l}\right)
$$

Substituting the relations for $\vec{J}_{p}$ (Equation (19)) and $\vec{J}_{l}$ (Equation (20)) into Equation (21), we obtain:

$$
\vec{U}_{p m}=(1-\phi)\left(\vec{U}_{p}-\vec{U}_{l}\right)=(1-\phi) \vec{U}_{s}
$$

where $\vec{U}_{s}=\left(\vec{U}_{p}-\vec{U}_{l}\right)$ is the slip velocity between the particles and the fluid (liquid).

The drift flux of particles, denoted as $\vec{J}_{p m}$, is related to the drift velocity of particles $\vec{U}_{p m}$ as:

$$
\vec{J}_{p m}=\phi \vec{U}_{p m}
$$

Substitution of Equations (21) into (23) yields:

$$
\vec{J}_{p m}=(1-\phi) \vec{J}_{p}-\phi \vec{J}_{l}
$$

From the knowledge of volumetric fluxes $\vec{J}_{p}, \vec{J}_{l}$ and volume fraction of particles $\phi$, one can calculate the drift flux using Equation (24). Once the drift flux is known, the drift velocity $\vec{U}_{p m}$ can be calculated from Equation (23) and the slip velocity $\vec{U}_{s}$ can be calculated from Equation (22).

The drift velocity can be expressed as:

$$
\vec{U}_{p m}=\vec{U}_{0} f(\phi)
$$

where $\vec{U}_{0}$ is the settling velocity of a single isolated particle in quiescent liquid and $f(\phi)$ is the hindered settling function of the form of Richardson and Zaki correlation. Thus,

$$
\vec{U}_{p m}=\vec{U}_{0}(1-\phi)^{n}
$$




$$
\vec{J}_{p m}=\phi \vec{U}_{p m}=\vec{U}_{0} \phi(1-\phi)^{n}
$$

In the absence of any relative motion or slip between the particles and fluid, we have:

$$
\vec{U}_{p m}=0 ; \vec{J}_{p m}=0 ; \vec{U}_{s}=0
$$

Under these conditions, the suspension flow can be treated as a homogeneous single-phase flow with average properties. In the present topic of discussion, that is, batch sedimentation of particles where there is no net flow of suspension, the following relations are applicable:

$$
\begin{gathered}
\vec{U}_{m}=0 \\
\vec{U}_{p m}=\vec{U}_{p} \\
\vec{J}_{p m}=\phi \vec{U}_{p} \\
\vec{U}_{p}=\vec{U}_{0}(1-\phi)^{n}
\end{gathered}
$$

\subsection{Re-interpretation of Existing Hindered Settling Data in Terms of Drift Flux Theory}

According to the drift flux model, the normalized drift velocity (see Equation (25)) is a function of the concentration of particles or droplets. The normalized drift velocity $U_{D r i f t, N}$ can be expressed in scalar form as:

$$
U_{D r i f t, N}=U_{p m} / U_{0}=(1-\phi)^{n}
$$

where the value of the exponent $n$ needs to be determined from experimental data. For low particle Reynolds number, the Richardson and Zaki correlation gives $n=4.65$.

Two sets of experimental data on creaming (upward motion) of oil droplets in concentrated

\begin{tabular}{|c|c|c|c|c|c|}
\hline Set No. & $\begin{array}{l}\text { Dispersion } \\
\text { Type }\end{array}$ & $\begin{array}{l}\text { Creaming or } \\
\text { Sedimentation }\end{array}$ & $\begin{array}{l}\text { Particle Volume } \\
\text { Fraction }\end{array}$ & $\begin{array}{l}\text { Particle Mean } \\
\text { Diameter }\end{array}$ & Reference \\
\hline 1 & emulsion & creaming & $0-0.40$ & $1.72 \mu \mathrm{m}$ & $\begin{array}{c}\text { Chanamai \& } \\
\text { McClements [43] }\end{array}$ \\
\hline 2 & emulsion & creaming & $0-0.40$ & $0.86 \mu \mathrm{m}$ & $\begin{array}{c}\text { Chanamai \& } \\
\text { McClements [43] }\end{array}$ \\
\hline 3 & suspension & sedimentation & $0-0.40$ & $788 \mu \mathrm{m}$ & Nicolai et al. [44] \\
\hline 4 & suspension & sedimentation & $0-0.48$ & $3.1 \mu \mathrm{m}$ & Buscall et al. [45] \\
\hline 5 & suspension & sedimentation & $0-0.15$ & $136 \mu \mathrm{m}$ & Davis \& Birdsell [46] \\
\hline 6 & suspension & sedimentation & $0-0.53$ & $0.27-0.31 \mu \mathrm{m}$ & Davis et al. [47] \\
\hline
\end{tabular}
oil-in-water emulsions and four sets of experimental data on settling of particles in concentrated suspensions are considered to validate the drift flux model, Equation (33). Table 1 provides the details of the emulsion and suspension systems considered here. The experimental data covers both creaming in emulsions and sedimentation in suspensions over broad ranges of droplet/particle concentration and sizes.

Table 1. Six sets of creaming/sedimentation data taken from different sources.

Figure 4 shows the experimental data for emulsions and suspensions plotted as normalized drift velocity versus droplet or particle concentration (vol. \%). Interestingly the experimental data for very different dispersed systems such as emulsions undergoing creaming effect (upward motion of oil droplets) and suspensions undergoing sedimentation effect (downward motion of particles), with very different droplet or particle sizes (see Table 1), show the same trend. However, there is a significant scatter of experimental data from one set to another. The likely cause for this scatter is the solvation of particles and droplets. The particles and droplets of dispersions become coated with thin layers or 
films of matrix fluid due to strong attractive interactions between the particle/droplet surfaces and the matrix molecules. The attractive interactions between the particle surface and matrix molecules are particularly important when the particles/droplets are electrically charged or the droplets are stabilized by surfactant (see Figure 5).

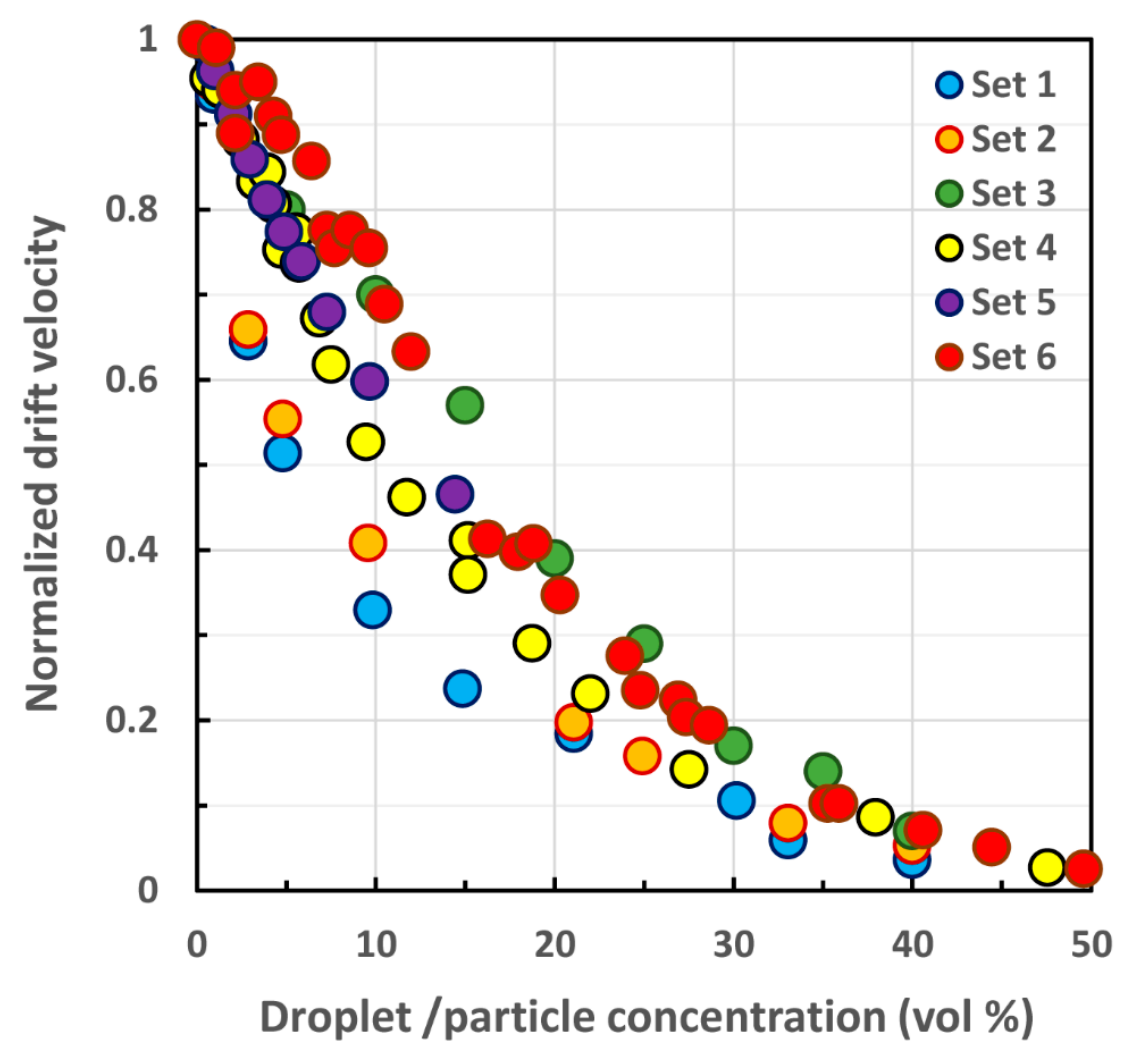

Figure 4. Experimental data for creaming/sedimentation of emulsions and suspensions plotted as normalized drift velocity versus droplet or particle concentration (vol. \%).

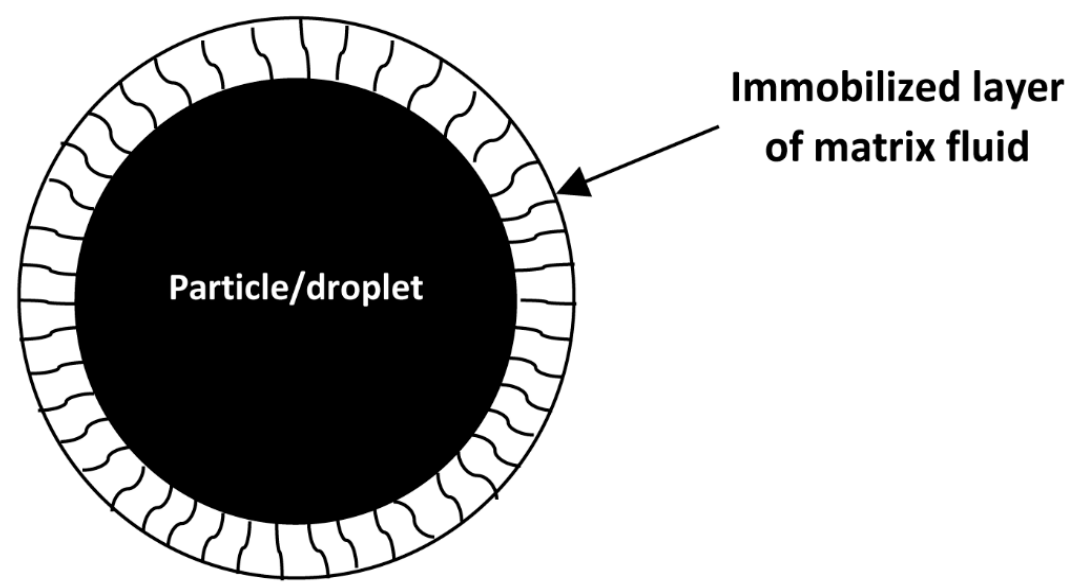

\section{Solvated particle/droplet}

Figure 5. Particle/droplet coated with a thin film of immobilized matrix fluid. 
The solvation films become part of the particles increasing their effective size and volume fraction. The effective volume fraction of solvated particles $\phi_{e f f}$ can be expressed as:

$$
\phi_{e f f}=\phi\left[1+\frac{\delta}{R}\right]^{3}=k_{s} \phi
$$

where $\delta$ is the solvation layer thickness, $R$ is the particle/droplet radius, and $k_{s}$ is the solvation coefficient. For a given solvation layer thickness $\delta$, the solvation effect increases with the decrease in droplet/particle radius. Thus the solvation effect cannot be ignored in dispersions of small size particles.

In order to take into account the effect of solvation of particles on creaming and sedimentation of particles, the volume fraction of un-solvated particles is replaced by $\phi_{e f f}$ in the expression for normalized drift velocity:

$$
U_{\text {Drift }, N}=U_{p m} / U_{0}=\left(1-\phi_{e f f}\right)^{n}=\left(1-k_{s} \phi\right)^{n}
$$

Using the Richardson and Zaki $n$ value of 4.65, one can estimate the solvation coefficient $k_{s}$ by re-arranging Equation (35) as:

$$
\left[U_{\text {Drift }, N}\right]^{1 / 4.65}=1-k_{s} \phi
$$

According to Equation (36), the plot of $\left[U_{D r i f t, N}\right]^{1 / 4.65}$ versus $\phi$ data is a straight line with a slope of $-k_{s}$. Figure 6 shows the typical plots of $\left[U_{D r i f t, N}\right]^{1 / 4.65}$ versus $\phi$ data. The data exhibit a linear relationship passing through $(0,1)$ with a slope of $-k_{s}$. Table 2 summarizes the values of the solvation coefficient for different systems. The solvation coefficients are large in the case of electrostatically stabilized emulsions consisting of small size droplets.

Table 2. Summary of solvation coefficients for different dispersed systems.

\begin{tabular}{cccccc}
\hline Set No. & $\begin{array}{c}\text { Dispersion } \\
\text { Type }\end{array}$ & $\begin{array}{c}\text { Creaming or } \\
\text { Sedimentation }\end{array}$ & $\begin{array}{c}\text { Solvation } \\
\text { Coefficient, } \boldsymbol{k}_{\boldsymbol{s}}\end{array}$ & $\begin{array}{c}\text { Particle Mean } \\
\text { Radius, } \boldsymbol{R}\end{array}$ & $\begin{array}{c}\text { Solvation Layer } \\
\text { Thickness, } \boldsymbol{\delta}\end{array}$ \\
\hline 1 & emulsion & creaming & 1.40 & $0.86 \mu \mathrm{m}$ & $0.102 \mu \mathrm{m}$ \\
2 & emulsion & creaming & 1.30 & $0.43 \mu \mathrm{m}$ & $0.039 \mu \mathrm{m}$ \\
3 & suspension & sedimentation & 1.0 & $394 \mu \mathrm{m}$ & $0 \mu \mathrm{m}$ \\
4 & suspension & sedimentation & 1.14 & $1.55 \mu \mathrm{m}$ & $0.069 \mu \mathrm{m}$ \\
5 & suspension & sedimentation & 1.11 & $68 \mu \mathrm{m}$ & $2.41 \mu \mathrm{m}$ \\
6 & suspension & sedimentation & 1.0 & $0.13-0.155 \mu \mathrm{m}$ & $0 \mu \mathrm{m}$ \\
\hline
\end{tabular}




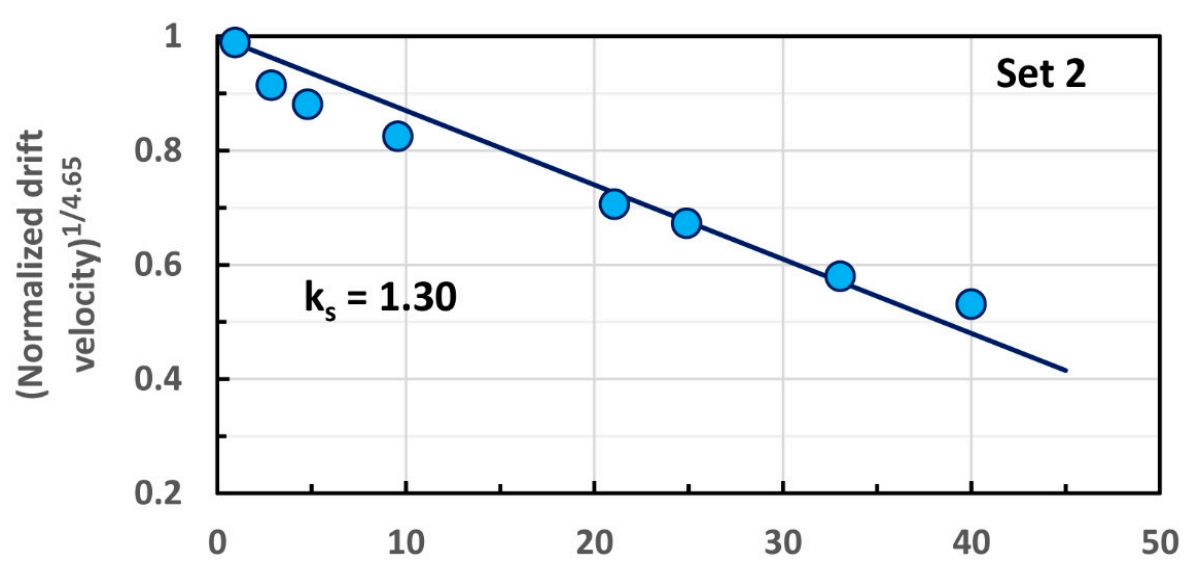

Droplet concentration (vol \%)
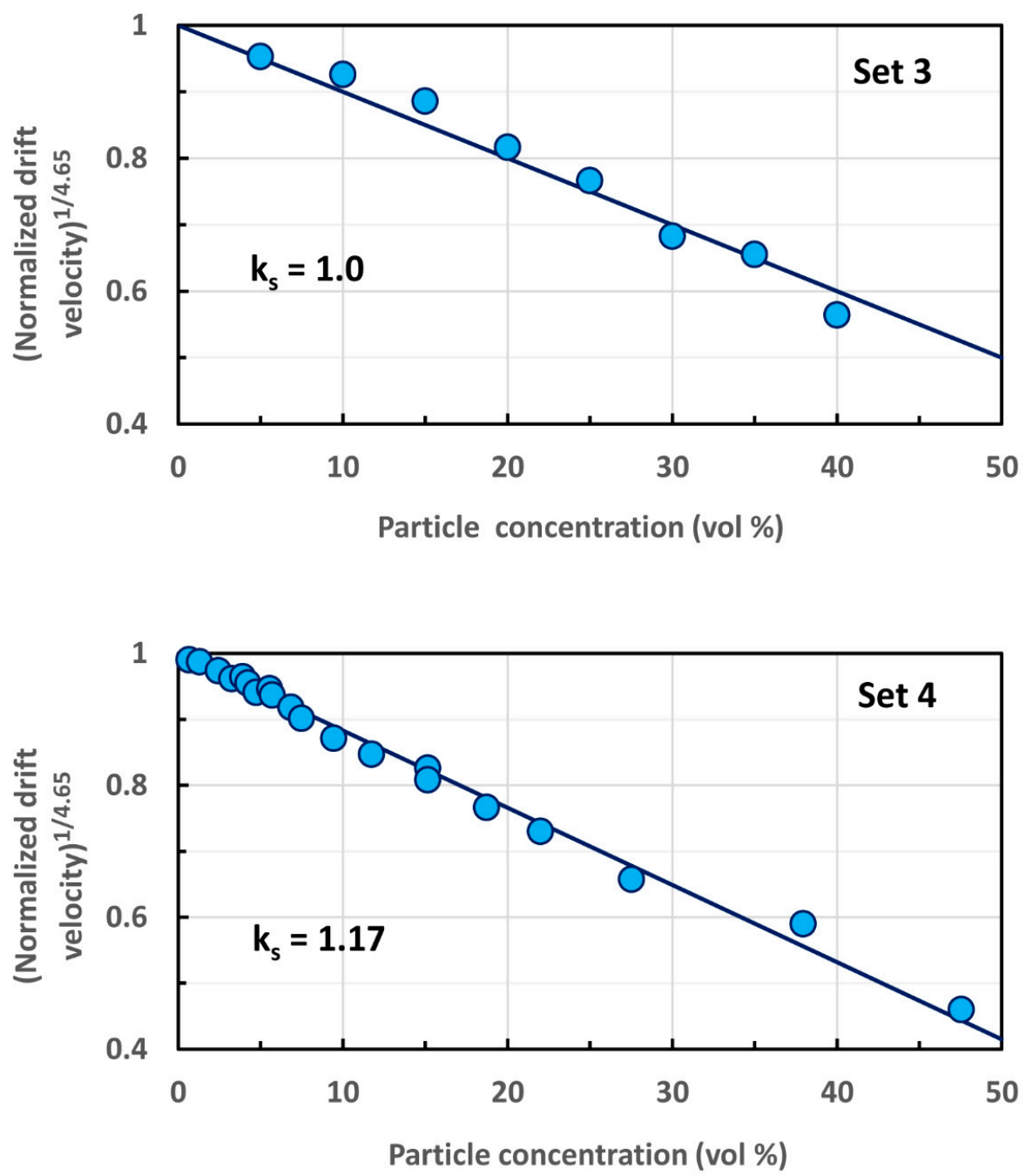

Figure 6. Typical plots of $\left[U_{D r i f t, N}\right]^{1 / 4.65}$ versus $\phi$ experimental data.

The experimental data for emulsions and suspensions are re-plotted in Figure 7 as normalized drift velocity versus effective volume fraction of particles/droplets $\phi_{e f f}($ vol. \%). Now the scatter in experimental data is reduced significantly and the following model describes the data adequately:

$$
U_{\text {Drift }, N}==\left(1-\phi_{e f f}\right)^{4.65}=\left(1-k_{s} \phi\right)^{4.65}
$$




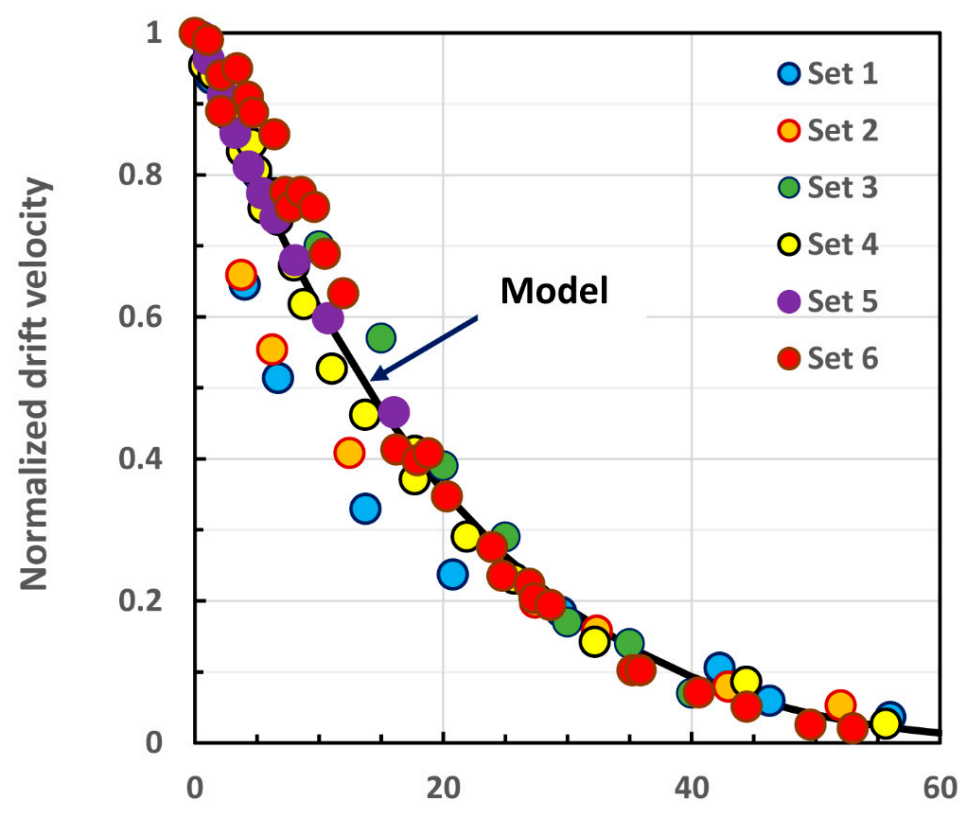

Effective dispersed-phase concentration (vol \%)

Figure 7. Normalized drift velocity versus effective volume fraction of particles/droplets $\phi_{e f f}$.

Figure 8 shows the plot of normalized drift flux $J_{d r i f t, N}$ as a function of effective dispersed-phase concentration $\phi_{e f f}$. The experimental data are compared with the following model for normalized drift flux:

$$
J_{\text {drift }, N}=J_{p m} / U_{0}=\phi_{\text {eff }}\left(1-\phi_{e f f}\right)^{4.65}
$$

where $\phi_{e f f}=k_{s} \phi$. The experimental data follow the drift flux model, Equation (38), reasonably well.

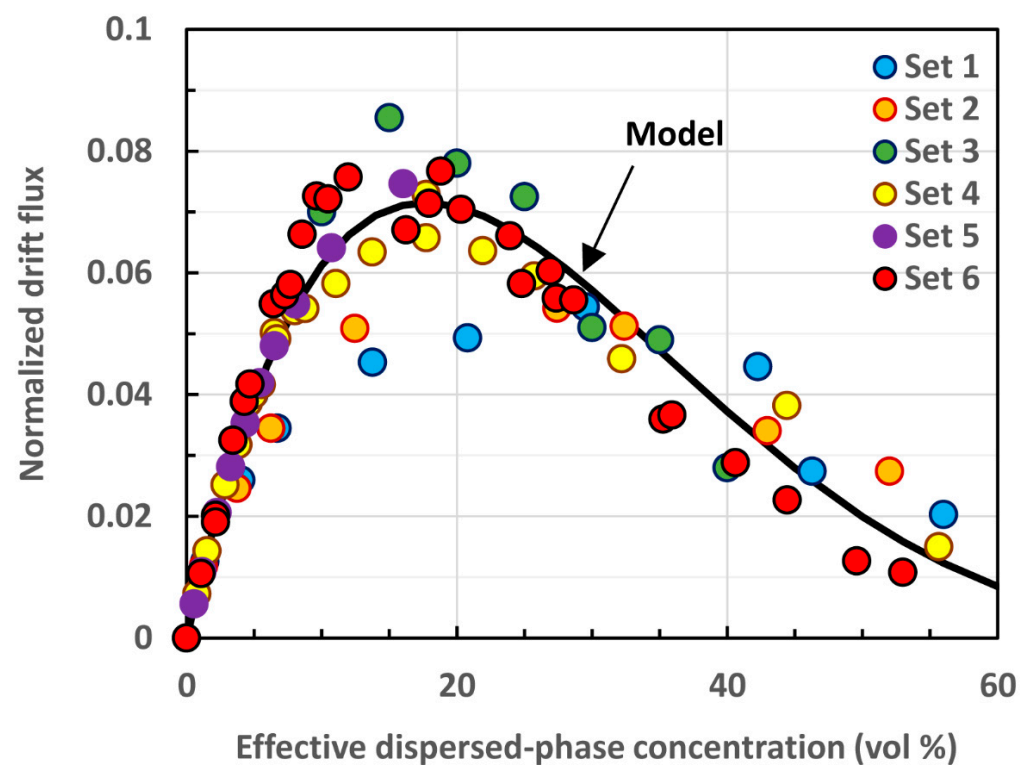

Figure 8. Normalized drift flux $J_{d r i f t, N}$ as a function of effective dispersed-phase concentration $\phi_{e f f}$ (vol \%).

In summary, the creaming and sedimentation experimental data obtained for a variety of different systems covering a broad range of particle and droplet sizes can be described adequately by the drift flux model, Equations (37) and (38). In what follows, this drift flux approach is applied to modeling of creaming and sedimentation of Pickering emulsions. 


\section{Modeling and Simulation of Creaming and Sedimentation of Pickering Emulsions}

\subsection{Upward Rise and Downward Settling of a Single Pickering Emulsion Droplet}

Consider a single Pickering emulsion droplet shown in Figure 9. The droplet has a core-shell morphology with liquid core and a monolayer of packed nanoparticles as a shell. The droplet may rise (cream) or settle (sediment) depending on the difference between the effective density of droplet and the density of matrix fluid.



Figure 9. Core-shell Pickering emulsion droplet.

Figure 10 shows a schematic diagram of a Pickering emulsion droplet with relevant dimensions. The effective density of the Pickering core-shell droplet is different from that of the bare droplet due to loading of nanoparticles at the interface. The effective density of core-shell droplets can be calculated using the following approach assuming a monolayer of spherical nanoparticles present on the droplet surface. The number of particles loaded on the droplet is:

$$
N=\frac{4 \pi\left(R^{*}\right)^{2}}{\pi R_{n p}^{2}} \beta=4\left(R^{*} / R_{n p}\right)^{2} \beta
$$

where $R_{n p}$ is the radius of the nanoparticle, $R^{*}$ is the radius of spherical surface passing through the equator of nanoparticles (see Figure 10), $\beta$ is the fraction of the surface area $4 \pi\left(R^{*}\right)^{2}$ occupied by the nanoparticles. For square packing of nanoparticles shown in Figure $11, \beta=0.785$. For hexagonal packing (see Figure 12), $\beta=0.907$.

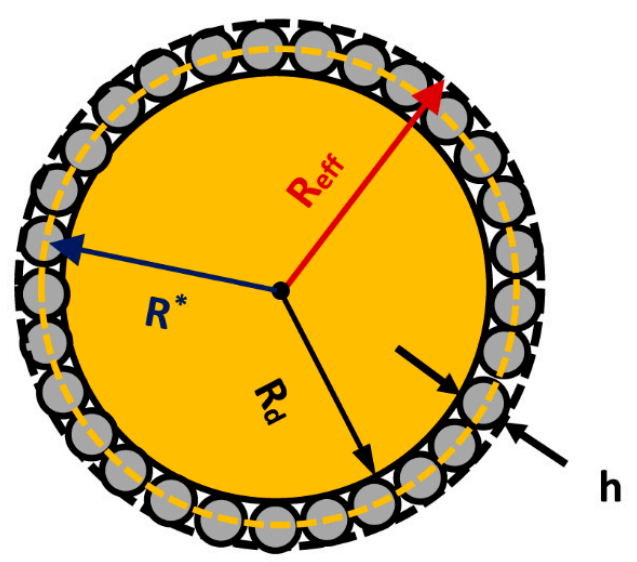

\section{$h=$ thickness of interfacial layer of nanoparticles protruding into the matrix fluid}

$\mathbf{R}_{\mathbf{d}}=$ radius of core droplet

$\mathbf{R}^{*}=$ radius of spherical surface passing through the equator of nanoparticles

\section{$R_{\text {eff }}=$ effective radius of the core- shell droplet $=\mathbf{R}_{\mathbf{d}}+\mathbf{h}$}

Figure 10. Schematic diagram of a Pickering emulsion droplet with relevant dimensions. 


\section{Square packing of nanoparticles}

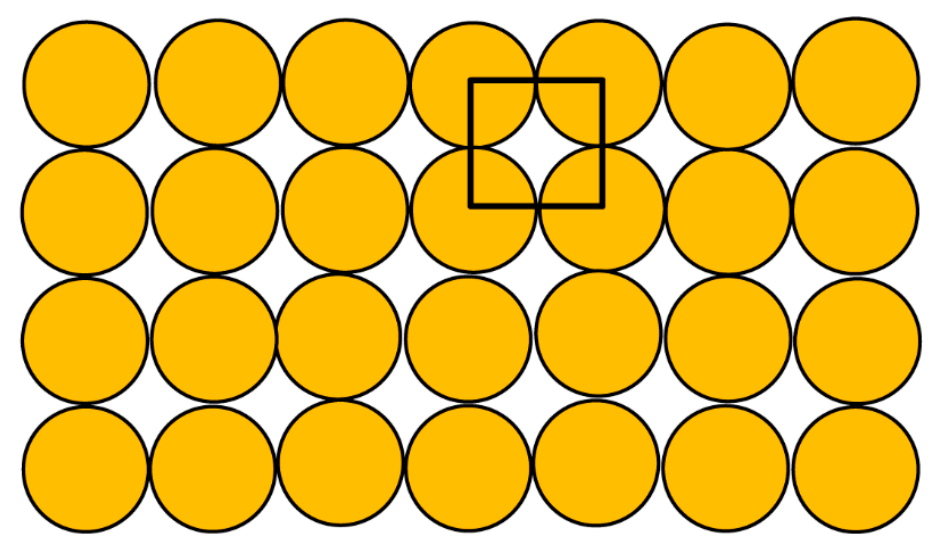

\section{Area occupied by circles $=\mathbf{7 8 . 5} \%$}

Figure 11. Square packing of nanoparticles.

\section{Hexagonal packing of nanoparticles}

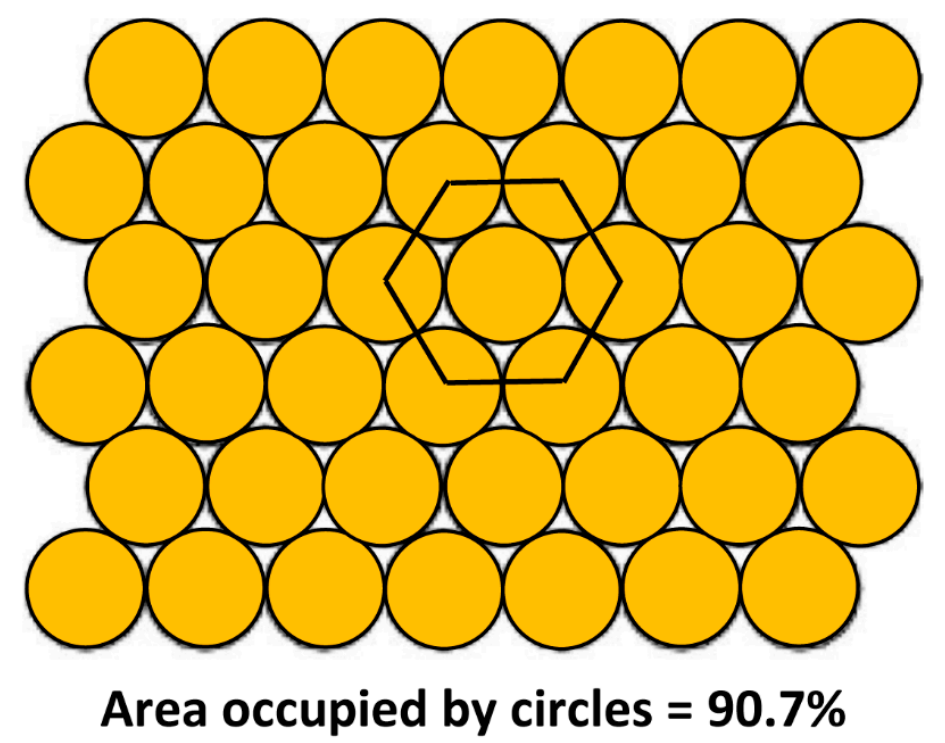

Figure 12. Hexagonal packing of nanoparticles.

\subsection{Oil-in-water $(\mathrm{O} / \mathrm{W})$ Emulsions}

For oil-in-water $(\mathrm{O} / \mathrm{W})$ emulsions, the thickness of the interfacial layer of nanoparticles protruding into the matrix aqueous fluid (see Figure 13) is given as follows [10]:

$$
h=R_{n p}(1+\cos \theta)
$$

where $\theta$ is the three-phase contact angle measured through the aqueous phase. The radius $R^{*}$ can be expressed as:

$$
R^{*}=R_{d}+h-R_{n p}=R_{d}\left(1+\frac{R_{n p}}{R_{d}} \cos \theta\right)
$$


where $R_{d}$ is the radius of bare emulsion droplet (see Figure 10). The mass of nanoparticles present on the surface of a single oil droplet can be calculated as follows:

$$
m_{\text {nanoparticles }}=N \rho_{n p}\left(4 \pi R_{n p}^{3} / 3\right)
$$

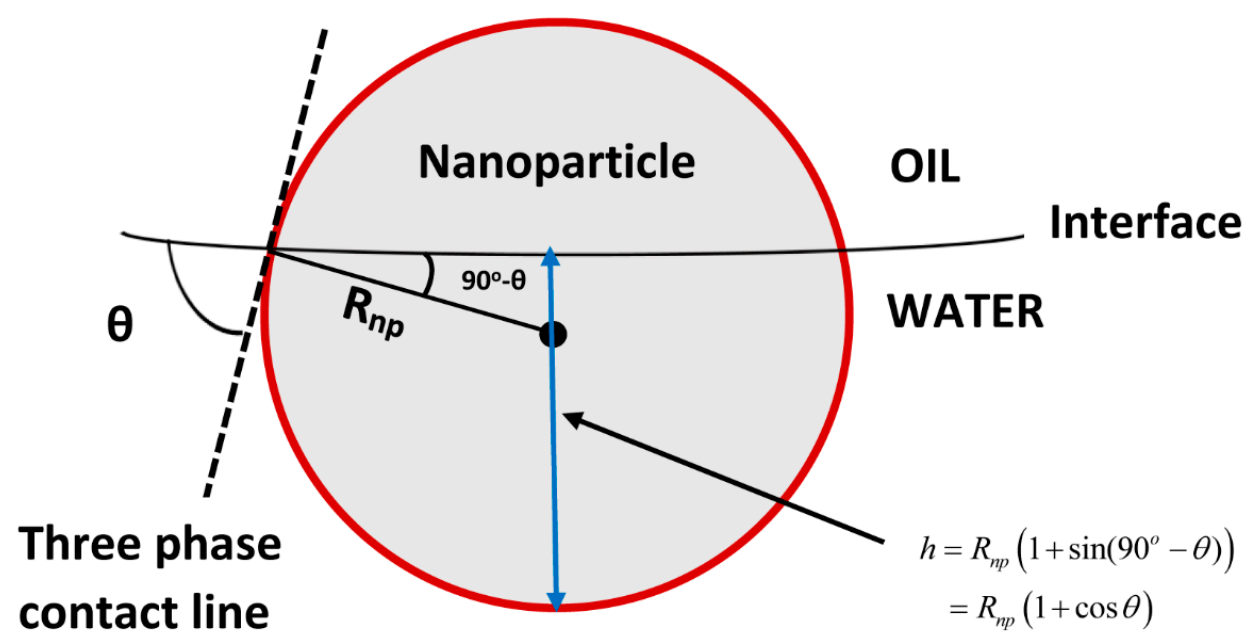

Figure 13. Thickness of interfacial layer of solid nanoparticles protruding into the continuous phase of an emulsion.

From Equations (39) and (42) it follows that:

$$
m_{\text {nanoparticles }}=(16 \pi / 3)\left(R^{*}\right)^{2} R_{n p} \beta \rho_{n p}
$$

The mass of the matrix fluid attached to the interfacial layer of nanoparticles is as follows:

$$
m_{\text {matrix-fluid-immobilized }}=N\left[4 R_{n p}^{2} h-(\pi / 3) h^{2}\left(3 R_{n p}-h\right)\right] \rho_{w}
$$

Thus the effective density of an oil droplet of a Pickering O/W emulsion can be expressed as:

$$
\rho_{d, e f f}=\left(m_{\text {bare-droplet }}+m_{\text {nanoparticles }}+m_{\text {matrix-fluid-immobilized }}\right) /\left(4 \pi R_{\text {eff }}^{3} / 3\right)
$$

where $R_{e f f}$ is the effective radius of the composite droplet $\left(R_{e f f}=R_{d}+h\right)$ and $m_{\text {bare-droplet }}$ is the mass of the bare oil droplet given as $\left(4 \pi R_{d}^{3} / 3\right) \rho_{o}$ where $\rho_{o}$ is the oil density.

Using the effective density of a droplet given by Equation (45), the rise velocity of a single Pickering oil droplet suspended in water matrix can now be calculated from the following modified Stokes law:

$$
U_{0}=\frac{2 g R_{e f f}^{2}\left(\rho_{w}-\rho_{d, e f f}\right)}{9 \mu}
$$

Figures 14 and 15 show the simulation results for two model Pickering O/W emulsions: PSNPMO-OW and SNPCO-OW, respectively. PSNPMO-OW refers to Pickering O/W emulsion consisting of polystyrene nanoparticles (PSNP) and mineral oil (MO) droplets. SNPCO-OW refers to Pickering $\mathrm{O} / \mathrm{W}$ emulsion consisting of silica nanoparticles (SNP) and castor oil (CO) droplets. For the PSNPMO-OW Pickering emulsion, the values of the various parameters used in the simulation are: $R_{d}=1 \mu \mathrm{m}, R_{n p}=0.1 \mu \mathrm{m}, \rho_{o}=773 \mathrm{~kg} / \mathrm{m}^{3}, \rho_{w}=997 \mathrm{~kg} / \mathrm{m}^{3}, \rho_{n p}=1054 \mathrm{~kg} / \mathrm{m}^{3}, \mu=0.89 \mathrm{mPa} . \mathrm{s}$, and $g=9.8 \mathrm{~m} / \mathrm{s}^{2}$. For the SNPCO-OW Pickering emulsion, the values of the various parameters used in the simulation are: $R_{d}=1 \mu \mathrm{m}, R_{n p}=0.1 \mu \mathrm{m}, \rho_{o}=960 \mathrm{~kg} / \mathrm{m}^{3}, \rho_{w}=997 \mathrm{~kg} / \mathrm{m}^{3}, \rho_{n p}=2650 \mathrm{~kg} / \mathrm{m}^{3}$, 
$\mu=0.89 \mathrm{mPa} . \mathrm{s}$, and $g=9.8 \mathrm{~m} / \mathrm{s}^{2}$. The Stokes (rise or fall) velocity $U_{o}$ and relative density $\rho_{d, e f f} / \rho_{o}$ of a single Pickering oil droplet are plotted as functions of contact angle. The solid curves are generated using $\beta=0.785$ (square packing of nanoparticles at the interface) and the dashed curves are generated using $\beta=0.907$ (hexagonal packing of nanoparticles at the interface).

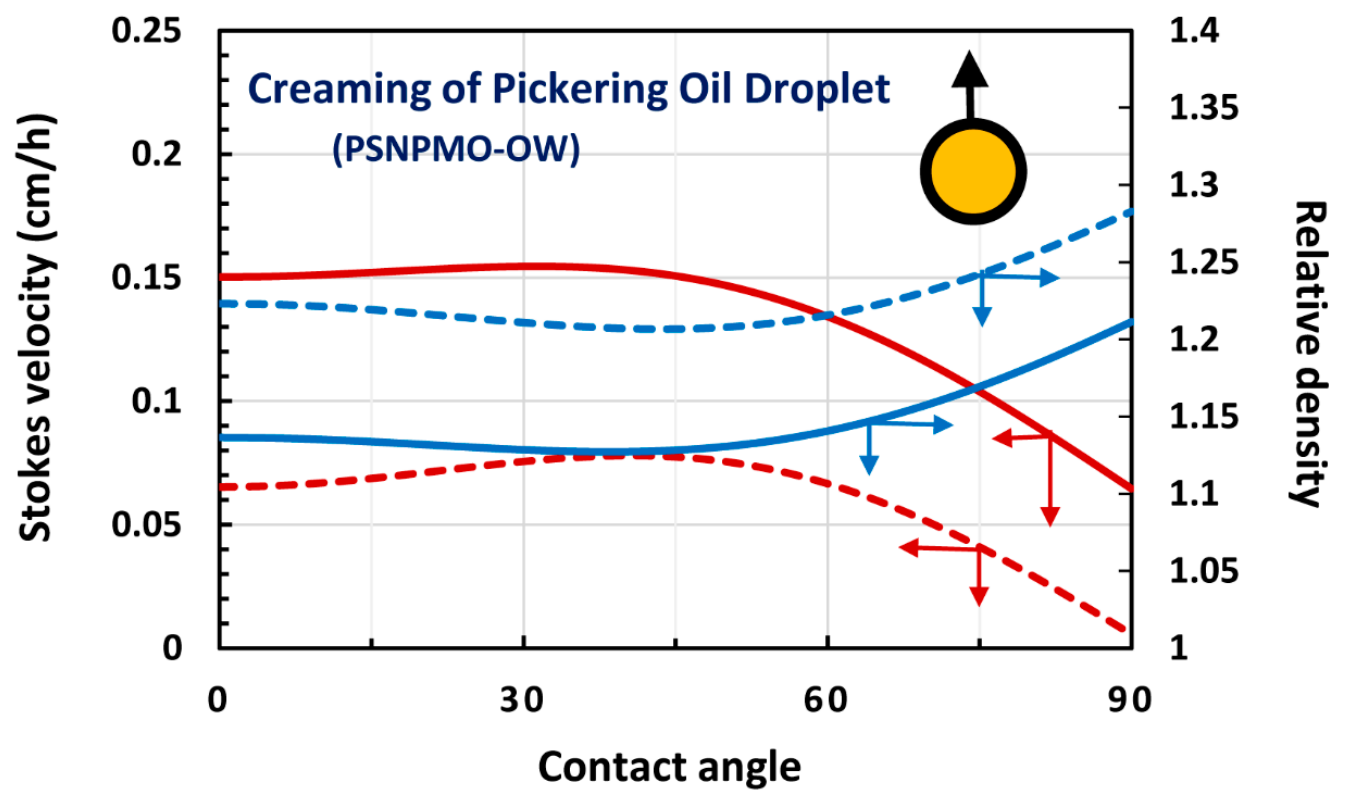

Figure 14. Variations of Stokes rise velocity and relative density of a single Pickering oil droplet with contact angle (PSNPMO-OW Pickering emulsion). The solid curves represent square packing and the dashed curves represent hexagonal packing of nanoparticles at the oil-water interface.

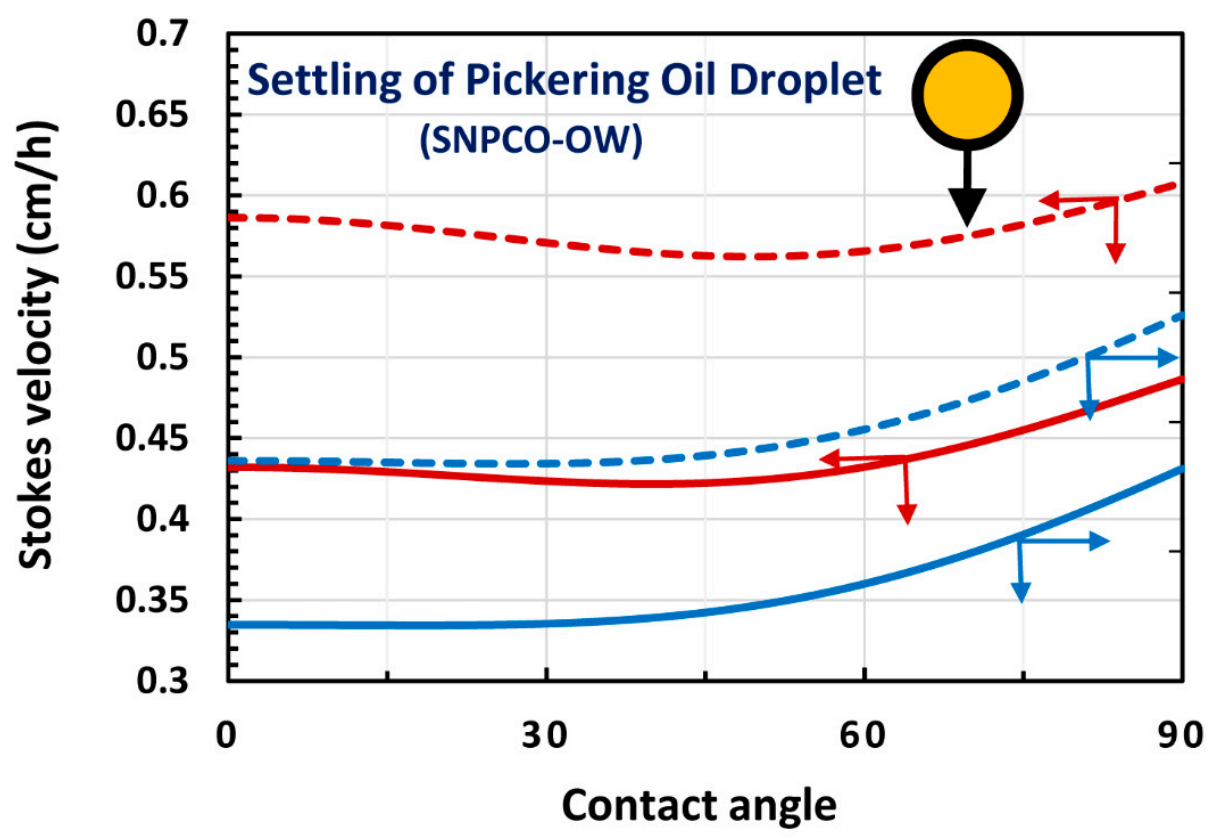

1.85

Figure 15. Variations of Stokes settling velocity and relative density of a single Pickering oil droplet with contact angle (SNPCO-OW Pickering emulsion). The solid curves represent square packing and the dashed curves represent hexagonal packing of nanoparticles at the oil-water interface. 
For the PSNPMO-OW Pickering emulsion (Figure 14), the Stokes rise velocity of a Pickering oil droplet increases initially with the increase in contact angle, reaches a maximum value, and then falls off with further increase in the contact angle. The relative density of a single composite droplet shows the opposite behavior in that the density initially decreases, reaches a minimum, and then rises with further increase in the contact angle. With the increase in contact angle initially from a value of zero, the mass of the attached high-density matrix fluid to the droplet is decreased as the matrix fluid is displaced with the increase in contact angle. Consequently the density of the composite droplet decreases and there occurs a corresponding increase in the Stokes rise velocity due to an increase in the density difference between the composite droplet and matrix fluid. However, with further increase in the contact angle, the amount of the matrix fluid displaced is little but the effective radius of the composite droplet becomes smaller and smaller resulting in an increase in the effective density of a composite droplet and the corresponding decrease in the Stokes velocity. Upon increasing the packing density of nanoparticles from square packing to hexagonal packing, the relative density curve of Pickering oil droplet shifts upward to higher densities, as expected. The Stokes rise velocity curve shows the opposite behavior in that it shifts to lower velocities due to decrease in the density difference between the Pickering oil droplet and matrix fluid.

For the SNPCO-OW Pickering emulsion (Figure 15), the composite oil droplets are no longer able to cream or rise in the matrix fluid as the effective density of the Pickering oil droplets exceeds the density of the matrix fluid. Note that the oil density $\left(\rho_{o}=960 \mathrm{~kg} / \mathrm{m}^{3}\right)$ is now close to that of the matrix fluid density $\left(\rho_{w}=997 \mathrm{~kg} / \mathrm{m}^{3}\right)$ and that the silica nanoparticles have a high density $\left(\rho_{n p}=2650\right.$ $\mathrm{kg} / \mathrm{m}^{3}$ ). The relative density and Stokes settling velocity of Pickering oil droplet increase with the increase in the contact angle. The relative density increases with the increase in the contact angle due to a decrease in the effective radius of the composite droplet. The Stokes settling velocity increases due to an increase in the density difference between the composite droplet and matrix fluid. With the increase in the packing density of nanoparticles from square packing to hexagonal packing, the relative density curve of Pickering oil droplet shifts upward to higher densities, as expected. The Stokes settling velocity curve also shifts upward to higher velocities due to an increase in the density difference between the Pickering oil droplet and matrix fluid.

\subsection{Water-in-oil (W/O) Emulsions}

For water-in-oil (W/O) emulsions, the thickness of the interfacial layer of nanoparticles protruding into the matrix fluid (oil) is given as follows [10]:

$$
h=R_{n p}(1-\cos \theta)
$$

where $\theta$ is the three-phase contact angle measured through the aqueous phase. The radius $R^{*}$ can be expressed as:

$$
R^{*}=R_{d}+h-R_{n p}=R_{d}\left(1-\frac{R_{n p}}{R_{d}} \cos \theta\right)
$$

The mass of nanoparticles present on the surface of a single water droplet can be calculated from Equation (43). The mass of the matrix fluid attached to the interfacial layer of nanoparticles is as follows:

$$
m_{\text {matrix-fluid-immobilized }}=N\left[4 R_{n p}^{2} h-(\pi / 3) h^{2}\left(3 R_{n p}-h\right)\right] \rho_{o}
$$

Thus the effective density of a water droplet of Pickering W/O emulsion can be expressed as:

$$
\rho_{d, e f f}=\left(m_{\text {bare-droplet }}+m_{\text {nanoparticles }}+m_{\text {matrix-fluid-immobilized }}\right) /\left(4 \pi R_{\text {eff }}^{3} / 3\right)
$$

where $R_{\text {eff }}$ is the effective radius of the composite droplet $\left(R_{\text {eff }}=R_{d}+h\right)$ and $m_{\text {bare-droplet }}$ is the mass of the bare water droplet given as $\left(4 \pi R_{d}^{3} / 3\right) \rho_{w}$ where $\rho_{w}$ is the water density. 
Using the effective density of a droplet given by Equation (50), the sedimentation or settling velocity of a single Pickering water droplet suspended in oil matrix can now be calculated from the following modified Stokes law:

$$
U_{0}=\frac{2 g R_{e f f}^{2}\left(\rho_{d, e f f}-\rho_{o}\right)}{9 \mu}
$$

Figures 16 and 17 show the simulation results for two model Pickering W/O emulsions: PSNPMO-WO and SNPCO-WO, respectively. PSNPMO-WO refers to Pickering W/O emulsion consisting of polystyrene nanoparticles (PSNP) and mineral oil (MO) matrix. SNPCO-WO refers to Pickering W/O emulsion consisting of silica nanoparticles (SNP) and castor oil (CO) matrix. The values of the parameters are the same as given earlier for the model Pickering O/W emulsions (PSNPMO-OW and SNPCO-OW) except for the matrix fluid viscosity $\mu$. For the PSNPMO-WO Pickering emulsion, the viscosity of the matrix fluid (mineral oil) is $2.5 \mathrm{mPa} . \mathrm{s}$ and for the SNPCO-WO Pickering emulsion, the viscosity of the matrix fluid (castor oil) is $650 \mathrm{mPa}$.s. The Stokes settling velocity $U_{o}$ and relative density $\rho_{d, e f f} / \rho_{w}$ of a single Pickering water droplet are plotted as functions of contact angle. The solid curves are generated using $\beta=0.785$ (square packing of nanoparticles at the interface) and the dashed curves are generated using $\beta=0.907$ (hexagonal packing of nanoparticles at the interface).

For both PSNPMO-WO and SNPCO-WO Pickering W/O emulsions, the effective density of the composite water droplet decreases with the increase in the contact angle from $90^{\circ}$ to $180^{\circ}$ due to an increase in the effective radius of the composite droplet. The Stokes settling velocity of a Pickering water droplet decreases with the increase in contact angle due to a decrease in the density difference between the composite droplet and matrix fluid. Upon increasing the packing density of nanoparticles from square packing to hexagonal packing, the relative density curve of Pickering water droplet shifts upward to higher densities, as expected. The Stokes settling velocity curve also shifts to higher velocities due to an increase in the density difference between the Pickering water droplet and matrix fluid (oil).

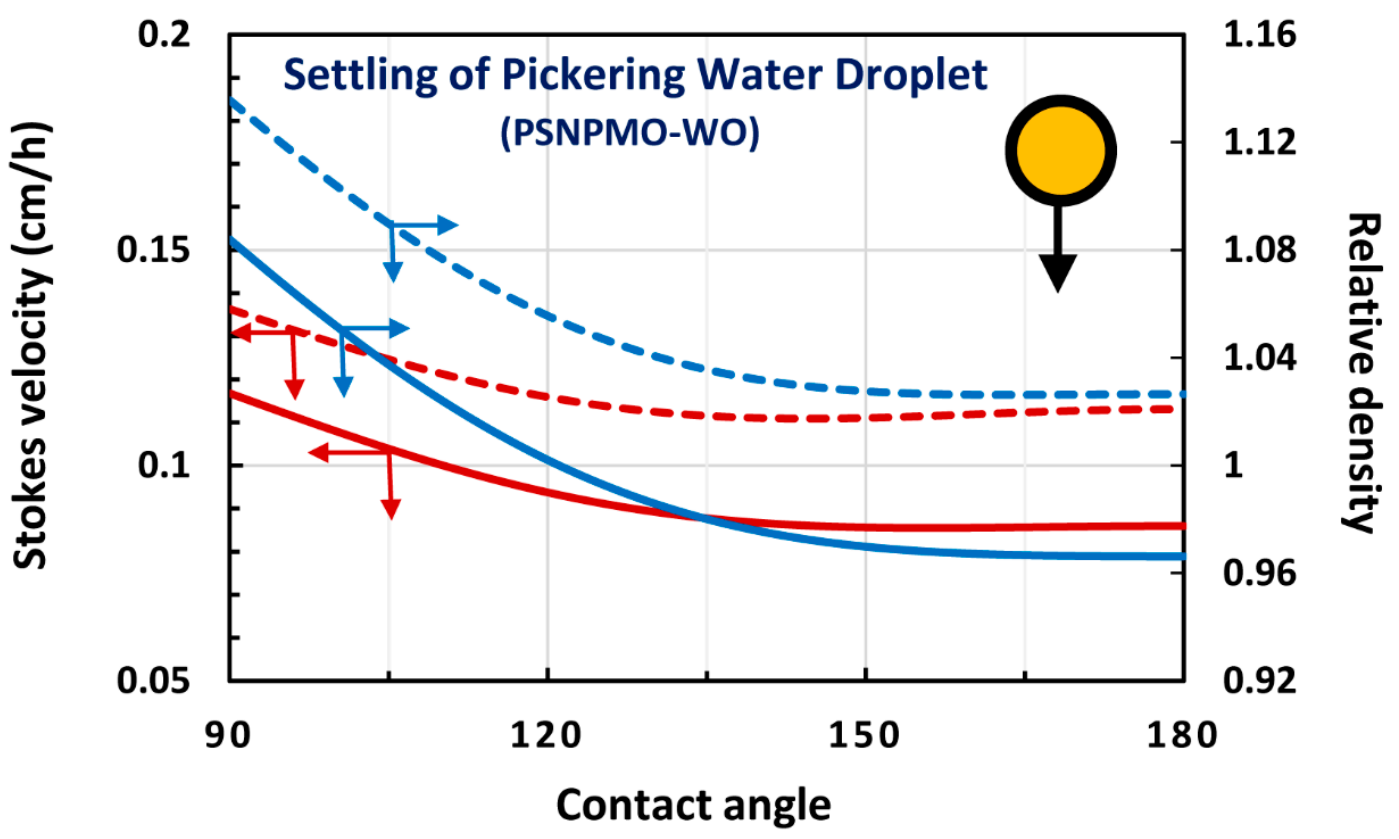

Figure 16. Variations of Stokes settling velocity and relative density of a single Pickering water droplet with contact angle (PSNPMO-WO Pickering emulsion). The solid curves represent square packing and the dashed curves represent hexagonal packing of nanoparticles at the oil-water interface. 


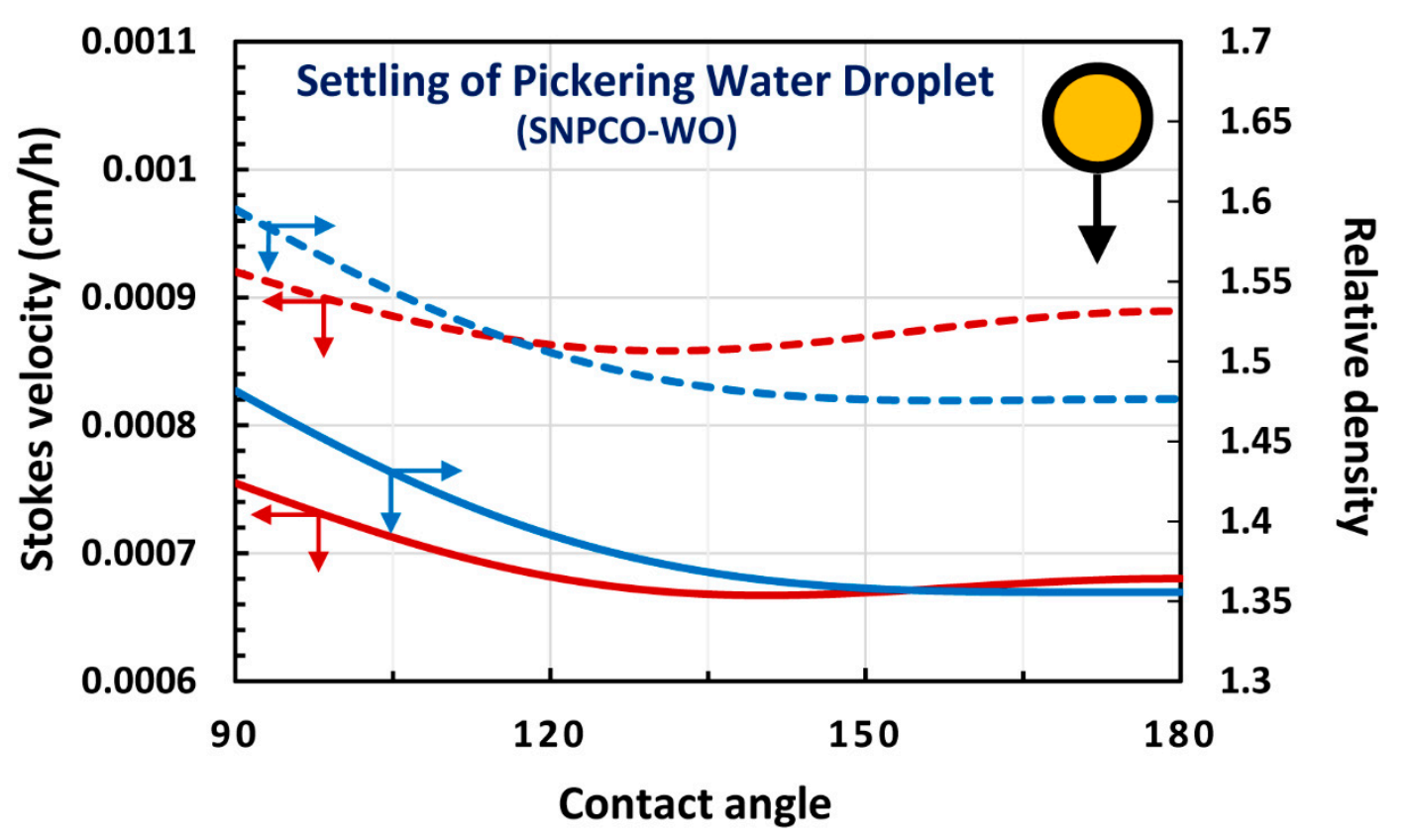

Figure 17. Variations of Stokes settling velocity and relative density of a single Pickering water droplet with contact angle (SNPCO-WO Pickering emulsion). The solid curves represent square packing and the dashed curves represent hexagonal packing of nanoparticles at the oil-water interface.

\subsection{Drift Flux of Emulsions}

As noted in Section 3.2, the normalized drift velocity $U_{\text {Drift }, \mathrm{N}}$ and the normalized drift flux $\mathrm{J}_{\mathrm{drift}, \mathrm{N}}$ for emulsions over a broad range of droplet concentration can be expressed as:

$$
\begin{gathered}
\mathrm{U}_{\text {Drift,N }}=\left(1-\phi_{\text {eff }}\right)^{4.65} \\
\mathrm{~J}_{\text {drift,N }}=\phi_{\text {eff }}\left(1-\phi_{\text {eff }}\right)^{4.65}
\end{gathered}
$$

where the effective volume fraction of Pickering droplets $\phi_{\text {eff }}$ is given as:

$$
\phi_{\mathrm{eff}}=\phi\left[1+\frac{h}{\mathrm{R}_{\mathrm{d}}}\right]^{3}
$$

The thickness $h$ of the interfacial layer of nanoparticles protruding into the matrix fluid is given by Equation (40) for $\mathrm{O} / \mathrm{W}$ emulsions and Equation (47) for W/O emulsions.

Figure 18 shows the plots of normalized drift flux $\mathrm{J}_{\mathrm{drift}, \mathrm{N}}$ versus $\phi$ for concentrated oil-in-water $(\mathrm{O} / \mathrm{W})$ emulsions for different values of contact angle. With the increase in contact angle, the normalized drift flux at high volume fractions of oil droplets increases due to a decrease in the effective volume fraction of the composite oil droplets.

Figure 19 shows the plots of normalized drift flux $J_{\text {drift,N }}$ versus $\phi$ for concentrated water-in-oil $(\mathrm{W} / \mathrm{O})$ emulsions for different values of contact angle. With the increase in contact angle from $90^{\circ}$ to $150^{\circ}$, the normalized drift flux at high volume fractions of water droplets decreases due to an increase in the effective volume fraction of the composite water droplets. 


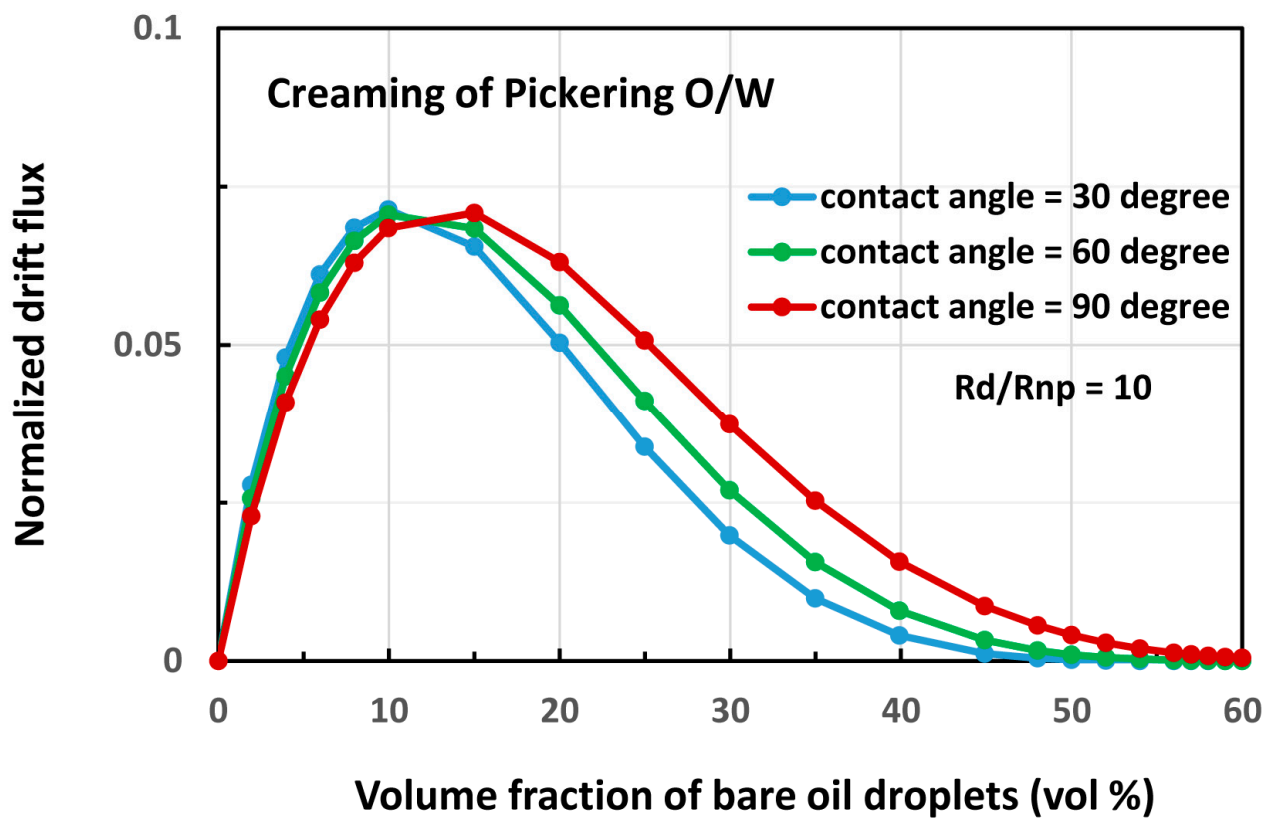

Figure 18. Effect of contact angle on normalized drift flux of Pickering $\mathrm{O} / \mathrm{W}$ emulsions.

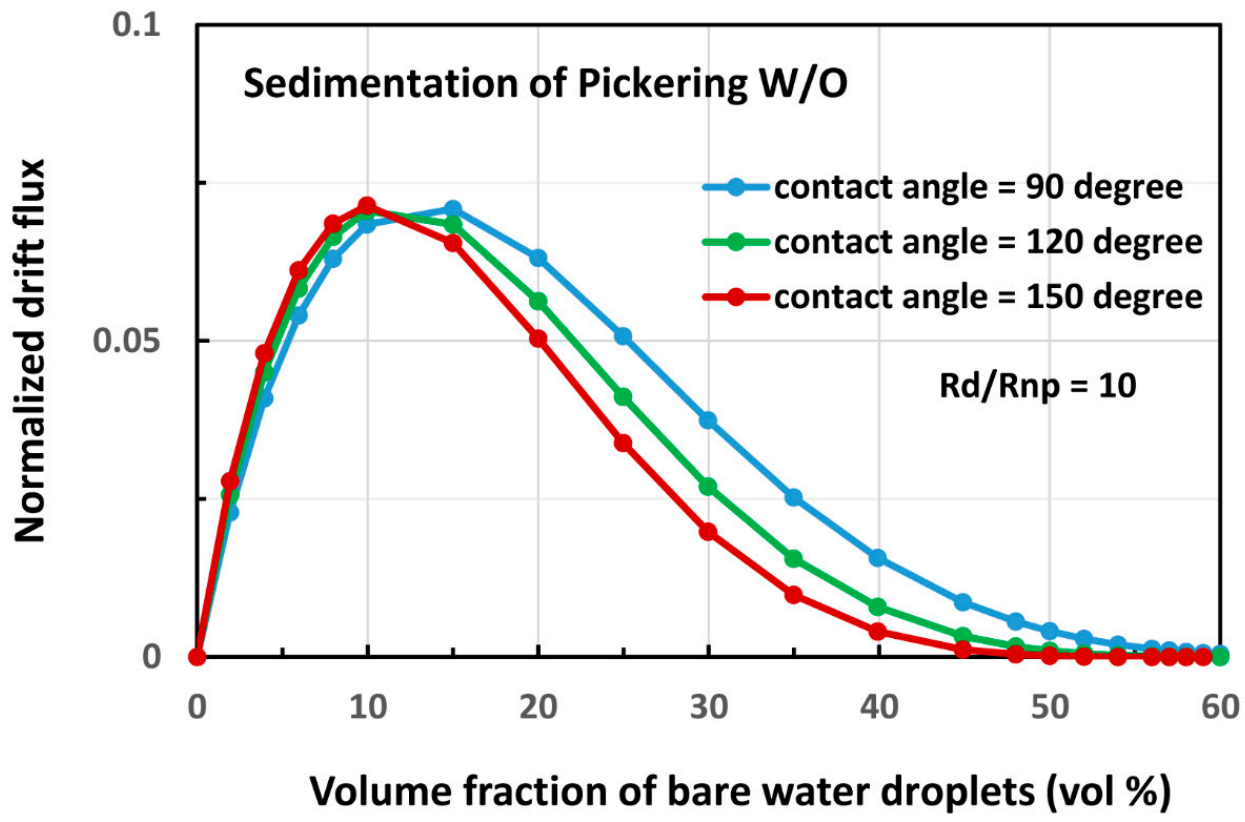

Figure 19. Effect of contact angle on normalized drift flux of Pickering W/O emulsions.

\section{Conclusions}

The creaming/settling behaviors of single droplet/particle and swarm of droplets/particles are reviewed briefly. The available experimental data on hindered creaming/settling of conventional emulsions and suspensions are interpreted in terms of a drift flux theory. The drift flux model describes the experimental data of creaming and sedimentation in conventional emulsions and suspensions adequately over a broad range of particle and droplet sizes provided that solvation of droplets/particles is taken into account. The unhindered and hindered creaming/settling behaviors of nanoparticle-stabilized Pickering emulsions are modelled. According to the proposed model, the key factors affecting the sedimentation and creaming of droplets in Pickering emulsions are: bare droplet size, size of nanoparticles, three-phase contact angle of the nanoparticles, and packing density of nanoparticles at the oil-water interface. The simulation results generated from the proposed model 
are presented and discussed. Experimental studies dealing with creaming/settling of single Pickering droplets and Pickering emulsions are lacking.

Funding: This research received no external funding.

Conflicts of Interest: The author declares no conflict of interest.

\section{Notation}

A parameter in Equation (13)

$A_{p} \quad$ projected area of particle

B parameter in Equation (13)

$C_{D} \quad$ drag coefficient

$D_{p} \quad$ diameter of particle

$F_{B} \quad$ buoyance force on the particle

$F_{D} \quad$ drag force on the particle

$F_{G} \quad$ gravity force (weight) on the particle

$F_{\text {net }} \quad$ net force on the particle

g acceleration due to gravity

$\mathrm{h}$ thickness of interfacial layer of nanoparticles protruding into the matrix fluid

$J_{l} \quad$ volumetric flux of liquid phase (units of velocity)

$J_{p} \quad$ volumetric flux of particles (units of velocity)

$J_{p m} \quad$ drift flux of particles (units of velocity)

$J_{\text {drift }, N} \quad$ normalized drift flux of particles

$k_{s} \quad$ solvation coefficient

m mass

$\mathrm{n} \quad$ exponent in Richarson and Zaki correlation, Equation (12)

$\mathrm{N}$ number of nanoparticles loaded on the Pickering droplet

$\mathrm{O} / \mathrm{W} \quad$ oil-in-water

$\mathrm{R} \quad$ radius of particle

$R_{d} \quad$ radius of core (bare) droplet

$R_{\text {eff }} \quad$ effective radius of composite (Pickering) droplet

$R_{n p} \quad$ radius of nanoparticles

$R^{*} \quad$ radius of spherical surface passing through the equator of nanoparticles (see Figure 10)

$R_{p} \quad$ particle Reynolds number

$t$ time

U velocity

$U_{\text {Drift }, N} \quad$ normalized drift velocity of particle

$U_{l} \quad$ liquid phase velocity

$U_{m} \quad$ mixture (suspension) velocity

$U_{0} \quad$ unhindered terminal velocity of particle

$U_{p} \quad$ settling velocity of particle in suspension (hindered settling)

$U_{p m} \quad$ drift velocity of particle

$U_{R} \quad$ dimensionless velocity defined in Equation (14)

$U_{S} \quad$ slip velocity between particle and matrix fluid

W/O water-in-oil

$\alpha \quad$ coefficient in Equation (11)

$\beta \quad$ packing density of nanoparticles at the oil-water interface

$\delta \quad$ thickness of solvation layer

$\varepsilon \quad$ volume fraction of fluid in a suspension

$\phi \quad$ actual volume fraction of particles/droplets

$\phi_{\text {eff }} \quad$ effective volume fraction of particles/droplets

$\mu \quad$ viscosity of matrix fluid

$\rho \quad$ density of matrix fluid

$\rho_{d, e f f} \quad$ effective density of composite (Pickering) droplet

$\rho_{n p} \quad$ density of nanoparticle

$\rho_{o} \quad$ density of oil 
$\rho_{p} \quad$ density of particle

$\rho_{w} \quad$ density of water

$\theta \quad$ contact angle

\section{References}

1. Pal, R. Rheology of Particulate Dispersions and Composites; CRC Press: Boca Raton, FL, USA, 2007.

2. Wu, J.; Ma, G.H. Recent studies of Pickering emulsions: Particles make the difference. Small 2006, 12, 4633-4648. [CrossRef] [PubMed]

3. Yang, Y.; Fang, Z.; Chen, X.; Zhang, W.; Xie, Y.; Chen, Y.; Liu, Z.; Yuan, W. An overview of Pickering emulsions: Solid-particle materials, classification, morphology, and applications. Front. Pharmacol. 2017, 3, 287. [CrossRef] [PubMed]

4. Berton-Carabin, C.C.; Schroen, K. Pickering emulsions for food applications: Background, trends, and challenges. Ann. Rev. Food Sci. Technol. 2015, 6, 263-297. [CrossRef] [PubMed]

5. Chevalier, Y.; Bolzinger, M.A. Emulsions stabilized with solid nanoparticles: Pickering emulsions. Colloids Surf. 2013, 439, 23-34. [CrossRef]

6. Dickinson, E. Use of nanoparticles and microparticles in the formation and stabilization of food emulsions. Trends Food Sci. Technol. 2012, 24, 4-12. [CrossRef]

7. Dickinson, E. Food emulsions and foams: Stabilization by particles. Curr. Opin. Colloid Interface Sci. 2010, 15, 40-49. [CrossRef]

8. Binks, B.P. Colloidal particles at a range of fluid-fluid interfaces. Langmuir 2017, 33, 6947-6963. [CrossRef]

9. Tarimala, S.; Wu, C.Y.; Dai, L.L. Pickering emulsions-A paradigm shift. In Proceedings of the AIChE Annual Meeting Conference Proceedings 2005, Cincinnati, OH, USA, 30 October-4 November 2005.

10. Pal, R. A simple model for the viscosity of Pickering emulsions. Fluids 2018, 3, 2. [CrossRef]

11. Bains, U.; Pal, R. In-situ continuous monitoring of the viscosity of surfactant-stabilized and nanoparticles-stabilized Pickering emulsions. Appl. Sci. 2019, 9, 4044. [CrossRef]

12. Rozynek, Z.; Bielas, R.; Jozefczak, A. Efficient formation of oil-in-oil Pickering emulsions with narrow size distributions by using electric fields. Soft Matter 2018, 14, 5140-5149. [CrossRef]

13. Timgren, A.; Rayner, M.; Dejmek, P.; Marku, D.; Sjoo, M. Emulsion stabilizing capacity of intact starch granules modified by heat treatment or octenyl succinic anhydride. Food Sci. Nutr. 2013, 1, 157-171. [CrossRef] [PubMed]

14. Zoppe, J.O.; Venditti, R.A.; Rojas, O.J. Pickering emulsions stabilized by cellulose nanocrystals grafted with thermos-responsive polymer brushes. J. Colloid Interface Sci. 2012, 369, 202-209. [CrossRef] [PubMed]

15. Chen, X.; Song, X.; Huang, J.; Wu, C.; Ma, D.; Tian, M.; Jiang, H.; Huang, P. Phase behavior of Pickering emulsions stabilized by graphene oxide sheets and resins. Energy Fuels 2017, 31, 13439-13447. [CrossRef]

16. Binks, B.P.; Fletcher, P.D.I.; Holt, B.L.; Beaussoubre, P. Phase inversion of particle-stabilized perfume oil-water emulsions: Experiment and theory. Phys. Chem. Chem. Phys. 2010, 12, 11954-11966. [CrossRef] [PubMed]

17. Fournier, C.O.; Fradette, L.; Tanguy, P.A. Effect of dispersed phase viscosity on solid-stabilized emulsions. Chem. Eng. Res. Des. 2009, 87, 499-506. [CrossRef]

18. Tsabet, E.; Fradette, L. Effect of the properties of oil, particles, and water on the production of Pickering emulsions. Chem. Eng. Res. Des. 2015, 97, 9-17. [CrossRef]

19. Simon, S.; Theiler, S.; Knudsen, A.; Oye, G.; Sjoblom, J. Rheological properties of particle-stabilized emulsions. J. Dispers. Sci. Technol. 2010, 31, 632-640. [CrossRef]

20. Li, C.; Liu, Q.; Mei, Z.; Wang, J.; Xu, J.; Sun, D. Pickering emulsions stabilized by paraffin wax and laponite clay particles. J. Colloid Interface Sci. 2009, 336, 314-321. [CrossRef]

21. Leclercq, L.; Nardello-Rataj, V. Pickering emulsions based on cyclodextrinx: A smart solution for antifungal azole derivatives topical delivery. Eup. J. Pharm. Sci. 2016, 82, 126-137. [CrossRef]

22. Crossley, S.; Faria, J.; Shen, M.; Resasco, D.E. Solid nanoparticles that catalyze biofuel upgrade reactions at the water/oil interface. Science 2010, 327, 68-72. [CrossRef]

23. Yang, B.; Leclercq, L.; Clacens, J.M.; Nardello-Rataj, V. Acidic/amphiphilic silica nanoparticles: New eco-friendly Pickering interfacial catalysis for biodiesel production. Green Chem. 2017, 19, 4552-4562. [CrossRef] 
24. Pera-Titus, M.; Leclercq, L.; Clacens, J.M.; De Campo, F.; Nardello-Rataj, V. Pickering interfacial catalysis for biphasic systems: From emulsion design to green reactions. Angew. Chem. Int. Ed. 2015, 54, 2006-2021. [CrossRef]

25. Leclercq, L.; Company, R.; Muhlbauer, A.; Mouret, A.; Aubry, J.M.; Nardello-Rataj, V. Versatile eco-friendly Pickering emulsions based on substrate/native cyclodextrin complexes: A winning approach for solvent-free oxidations. ChemSusChem 2013, 6, 1533-1540. [CrossRef] [PubMed]

26. Leclercq, L.; Mouret, A.; Proust, A.; Schmitt, V.; Bauduin, P.; Aubry, J.M.; Nardello-Rataj, V. Pickering emulsions stabilized by catalytic polyoxometalate nanoparticles: A new effective medium for oxidation reactions. Chem. Eur. J. 2012, 18, 14352-14358. [CrossRef] [PubMed]

27. Kaptay, G. On the equation of the maximum capillary pressure induced by solid particles to stabilize emulsions and foams and on the emulsion stability diagrams. Colloids Surf. A 2006, 282/283, 387-401. [CrossRef]

28. Katepalli, H.; John, V.T.; Tripathi, A.; Bose, A. Microstructure and rheology of particle stabilized emulsions: Effects of particle shape and inter-particle interactions. J. Colloid Interface Sci. 2017, 485, 11-17. [CrossRef]

29. Braisch, B.; Kohler, K.; Schuchmann, H.P.; Wolf, B. Preparation and flow behavior of oil-in-water emulsions stabilized by hydrophilic silica particles. Chem. Eng. Technol. 2009, 32, 1107-1112. [CrossRef]

30. Ganley, W.J.; Van Duijneveldt, J.S. Controlling the rheology of montmorillonite stabilized oil-in-water emulsions. Langmuir 2017, 33, 1679-1686. [CrossRef]

31. Hermes, M.; Clegg, P.S. Yielding and flow of concentrated Pickering emulsions. Soft Matter 2013, 9, 7568-7575. [CrossRef]

32. Ogunlaja, S.B.; Pal, R.; Sarikhani, K. Effects of starch nanoparticles on phase inversion of Pickering emulsions. Can. J. Chem. Eng. 2018, 96, 1089-1097. [CrossRef]

33. Malhotra, V.; Pal, R.; Alhassan, S. Catastrophic phase inversion of emulsions stabilized by amphiphilic nanoparticles. J. Nanofluids 2018, 7, 30-36. [CrossRef]

34. Pal, R.; Malhotra, V. Influence of hybrid nanoparticle-surfactant stabilizers on catastrophic phase inversion of emulsions. J. Nanofluids 2018, 7, 300-308. [CrossRef]

35. Sihler, S.; Schrade, A.; Cao, Z.; Ziener, U. Inverse Pickering Emulsions with Droplet Sizes below $500 \mathrm{~nm}$. Langmuir 2015, 31, 10392-10401. [CrossRef] [PubMed]

36. Becher, P. Emulsions: Theory and Practice; Reinhold Publishing Corp: New York, NY, USA, 1957.

37. Robins, M.M. Emulsions-creaming phenomena. Curr. Opin. Colloid Interface Sci. 2000, 5, 265-272. [CrossRef]

38. Becher, P. (Ed.) Encyclopedia of Emulsion Technology: Basic Theory; Marcel Dekker: New York, NY, USA, 1983.

39. Batchelor, G.K. Sedimentation in a dilute dispersion of spheres. J. Fluid Mech. 1972, 52, 245-268. [CrossRef]

40. Richardson, J.F.; Zaki, W.N. Sedimentation and fluidization. Trans. Inst. Chem. Eng. 1954, 32, 35-53.

41. Garside, J.; Al-Dibouni, M.R. Velocity-voidage relationships for fluidization and sedimentation in solid-liquid systems. Ind. Eng. Chem. Process Des. Dev. 1977, 16, 206-214. [CrossRef]

42. Al-Naafa, M.A.; Sami Selim, M. Sedimentation of monodisperse and bidisperse hard-sphere colloidal suspensions. AIChE J. 1992, 38, 1618-1630. [CrossRef]

43. Chanamai, R.; McClements, D.J. Dependence of creaming and rheology of monodisperse oil-in-water emulsions on droplet size and concentration. Coll. Surf. A Physicochem. Eng. Asp. 2000, 172, 79-86. [CrossRef]

44. Nicolai, H.; Herzhaft, B.; Hinch, E.J.; Oger, L.; Guazzelli, E. Particle velocity fluctuations and hydrodynamic self-diffusion of sedimenting non-Brownian spheres. Phys. Fluids 1995, 7, 12-23. [CrossRef]

45. Buscall, R.; Goodwin, J.W.; Ottewill, R.H.; Tadros, T.F. The settling of particles through Newtonian and non-Newtonian media. J. Colloid Interface Sci. 1982, 85, 78-86. [CrossRef]

46. Davis, R.H.; Birdsell, K.H. Hindered settling of semidilute monodisperse and polydisperse suspensions. AIChE J. 1988, 34, 123-129. [CrossRef]

47. Davis, K.E.; Russel, W.B.; Glantschnig, W.J. Settling suspensions of colloidal silica: Observations and x-ray measurements. J. Chem. Soc. Faraday Trans. 1991, 87, 411-424. [CrossRef]

(C) 2019 by the author. Licensee MDPI, Basel, Switzerland. This article is an open access article distributed under the terms and conditions of the Creative Commons Attribution (CC BY) license (http://creativecommons.org/licenses/by/4.0/). 